\title{
A JUSTIÇA DAS VÍTIMAS: FUNDAMENTO ÉTICO E PERSPECTIVA HERMENÊUTICA
}

\author{
Castor M.M. Bartolomé Ruiz
}

RESUMO - Este trabalho pretende realizar uma reflexão crítica sobre sentido moderno da justiça procedimental, desenvolvendo uma nova hermenêutica da justiça a partir da alteridade das vítimas.

PALAVRAS-CHAVE - Justiça procedimental. Ética. Hermenêutica. Alteridade.

\author{
ABSTRACT - This paper is about a critics \\ reflection to a modern sense of proceeding \\ justice, developing a new hermeneutics of justice \\ to alterity of victims. \\ KEY WORDS - Proceeding justice. Ethics. Her- \\ meneutics. Alterity.
}

\section{A justiça em perspectiva}

A justiça é um valor e uma prática: uma prática valorativa. Por isso os sentidos da justiça são sempre uma valoração da práxis, uma hermenêutica da ação humana. A hermenêutica põe os valores na roda das perspectivas, e a verdade sobre os valores se torna uma questão relativa ao ponto de vista adotado. Por sua vez, a relatividade dos valores está perpassada pelos interesses em jogo e pelos seus efeitos de poder. A justiça não escapa ao perspectivismo ético nem ao seu potencial relativismo. Esta é uma das grandes questões de nossos tempos pósmodernos.

Para encontrar os fundamentos da justiça não podemos pensar mais a justiça de modo jusnaturalista nem apegar-nos a um mundo objetivo de valores. Contudo, a tese que queremos defender neste trabalho é que a perspectiva hermenêutica da justiça não desemboca inexoravelmente no niilismo. Nossa tese é que a justiça enquanto prática está sempre co-referida à alteridade humana. Esta não determina o sentido da justiça, porém delimita os critérios daquilo que pode ser considerado justo. Os sentidos da justiça são sempre correlativos à alteridade humana.

O trabalho analisa e contrasta três grandes perspectivas éticas: a prática da virtude (teleológica), o procedimentalismo (deontológica) e a alteridade. Num primeiro momento desenvolvemos uma análise da justiça como virtude a partir de Aristóteles, rastreando a presença e ausência da alteridade nessa perspectiva.

UNISINOS, São Leopoldo - castor@netu.unisinos.br

\begin{tabular}{|l|l|l|l|l|l|}
\hline VERITAS & Porto Alegre & v. 52 & n. 2 & Junho 2007 & p. 22-34 \\
\hline
\end{tabular}


Num segundo momento analisamos criticamente o conceito de justiça procedimental, mostrando algumas das suas contribuições e muitas das suas deficiências, em especial sua falta de perspectiva da alteridade. Por último, tomando como referência principal, ainda que não exclusiva, a obra de Levinas, propomos uma reconsideração da alteridade como critério hermenêutico para a constituição do sentido da justiça.

\section{Justiça e alteridade em Aristóteles}

No caleidoscópio que cruza as interpretações éticas e os interesses sociais, a justiça foi significada com muitos sentidos. Para os clássicos ela foi considerada uma virtude, a virtude principal em torno da qual todas as demais adquirem seu sentido. Aristóteles, em seu livro V da Ética a Nicômaco, define a justiça como "uma qualidade moral", que obriga os homens a praticar coisas justas. De igual forma, caracteriza a injustiça como "uma qualidade moral" que induz as pessoas a praticarem o injusto. ${ }^{1}$ Para Aristóteles, embora a justiça seja uma qualidade moral, ela está submetida a diversas interpretações sobre o que seja justo. Entre os diversos critérios adotados para definir o justo está o que Aristóteles denomina de justo meio. Porém esse critério ainda resulta insuficiente para definir a justiça.

Outro critério de justiça proposto por Aristóteles é a obediência às leis. Segundo o mesmo, justo é aquele que obedece às leis estabelecidas e observa com os demais as regras da igualdade; justiça será aquilo que é conforme à lei e à igualdade, e, vice-versa, injustiça será o que é ilegal e desigual. ${ }^{2}$

Considerar a virtude da justiça em correlação à lei e à igualdade não resolve o relativismo ético nem livra a justiça dos jogos de poder que a cercam. Nessa perspectiva, a justiça fica à mercê da ordem legal estabelecida e dos sentidos que ela dá à igualdade social. Por sua vez o critério do justo meio não ajuda muito para definir a ordem legal justa nem a igualdade social, já que cada um pode considerar seus interesses como justos situando-os num hipotético justo meio entre outros dois hipotéticos extremos.

A identificação do justo com o legal leva inexoravelmente a absolutizar o legal como paradigma do justo, chegando a afirmar Aristóteles que "é evidente que todas as coisas legais são de algum modo justas". ${ }^{3}$ Esta afirmação, na prática, se mostra profundamente contraditória. Aristóteles justifica essa vinculação incondicional da justiça à lei por considerar como evidente que todas as leis têm por objetivo o interesse geral de todos os cidadãos. ${ }^{4}$ Essa é outra "evidência" nada convincente diante de tantos exemplos históricos que a contradizem.

Embora a justiça, em Aristóteles, esteja mediatizada pelo legalismo e pelo critério subjetivo comum às outras virtudes, ele considera que a justiça é a única

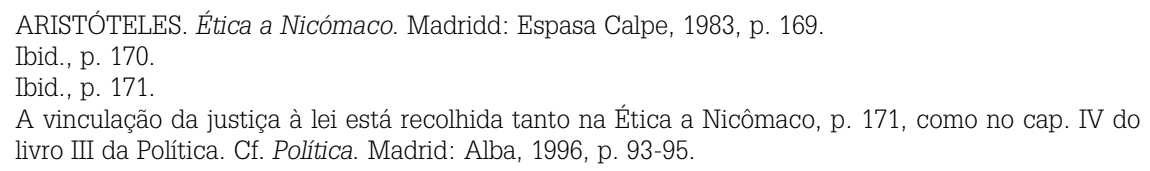


virtude que existe em relação ao outro. As outras virtudes têm como referência o sujeito que pretende ser virtuoso, porém a justiça exige a presença do outro para realizar-se como virtude. Alguém é justo, fundamentalmente, com o outro, e só de forma metafórica podemos dizer que alguém é justo consigo mesmo. A justiça não se aplica como virtude para si mesmo ela é virtude em relação ao outro. O outro se torna critério do sentido da justiça. A prática da justiça faz a pessoa justa, mas o justo está sempre em relação ao outro para quem realiza a justiça. É uma contradição pensar que alguém é justo fazendo o bem só para si mesmo. Alguém se torna justo porque realiza o bem para o outro; esse é o sentido da justiça. A justiça está co-referida sempre a um outro, por isso é exaltada por Aristóteles como a maior das virtudes. Ao realizar-se em relação a um outro, a justiça realiza a plenitude de todas as virtudes. "(A justiça) é a virtude no sentido pleno, porque é a prática da virtude perfeita, e é perfeita, porque aquele que a possui pode fazer uso da virtude com os outros e não consigo mesmo". ${ }^{5}$ Para Aristóteles a injustiça é um vício que, devido ao impacto que provoca no outro, "não é parte do vício, mas a totalidade do vício". 6

Embora Aristóteles reconheça e destaque a importância do outro com relação à virtude da justiça, esse reconhecimento é secundário no contexto de sua ética. Para Aristóteles, a prática da virtude tem como referência primeira o sujeito que pretende tornar-se virtuoso. O outro é uma referência necessária na virtude da justiça, mas secundária no modelo de ética e política proposto por ele. Na prática da virtude, o sujeito adota os princípios de sua racionalidade como critérios valorativos de seu agir. O principal objetivo da prática da virtude é a constituição da subjetividade, para isso a referência valorativa do sujeito é a eudaimonía. Ser feliz se constitui em meta e método, o outro é o meio para atingir esse fim. Entre a ética eudemonista e o sujeito existe uma espécie de circularidade pela qual o sujeito se coloca a si mesmo como objetivo e critério de sua ação ética.

Poderíamos pensar que a circularidade ética, em Aristóteles, não é totalmente fechada, porque a busca da felicidade é correlativa à realização do bem e da justiça. Porém, há uma tensão não-resolvida entre a razão e a alteridade na teoria de Aristóteles. Embora ele tenha reconhecido que o outro é a referência hermenêutica fundamental para o sentido da justiça, o bem e a justiça são correlativos à razão e não à alteridade; nisso segue a Sócrates. A razão é entendida como razão prática das verdades naturais que retira o sujeito da aporia do subjetivismo. $\mathrm{O}$ bem, a justiça e a verdade dos demais valores são definidos de modo racional. Contudo, para Aristóteles a razão não pode ser identificada como a racionalidade da natureza, o com o logos universal, como nos estóicos, nem com o mundo lógico das idéias proposto por Platão.

Aristóteles aceita a existência do bem e da justiça como valores inerentes à razão. É a razão do sujeito que define segundo os critérios racionais práticos, o

ARISTÓTELES. Ética Nicomacaquea. (1130a) Madrid: Gredos, 2000, p. 241.

ARISTÓTELES. Ética a Nicómaco. Madrid: Espasa Calpe, 1983, p. 172. 
que é bom e justo na prática da virtude. É a razão do sujeito, ou o sujeito, através da racionalidade, que delibera o que é bom e justo.

Para Aristóteles, o método de discernimento do bem e da justiça se efetiva, a partir da razão do sujeito. É um método racionalista prático; nele, a alteridade é considerada uma categoria colateral da lógica. O outro não tem relevância suficiente para ser critério daquilo que deve ser considerado bom e justo. Na teoria da virtude de Aristóteles, a alteridade não consegue ser um critério para o discernimento do bem e da justiça. A racionalidade do sujeito é considerada como o único modo de "conhecer" o que é bom e justo. Com isso, o bem e a justiça são, em primeiro lugar, objeto de conhecimento teorético para posteriormente realizar-se como prática da virtude. A theoría do logos suplanta com auto-suficiência a alteridade. O outro não é referência epistemológica (suficiente) para poder definir o que é bom e justo. O sujeito pode discernir, pelo uso da sua racionalidade, com total "autonomia" (uma autonomia auto-suficiente) sobre o bem e o mal, sobre o justo e o injusto.

Como conseqüência do anteriormente exposto, a injustiça é considerada um vício, o vício mais grave. Porém, ao analisar a injustiça, não se considera que é vítima da mesma seja um critério epistemológico para definir o sentido do justo e do injusto. A vítima é invisível na epistemologia da virtude. O sofrimento do injustiçado não é considerado como critério de validação da justiça. A alteridade negada da vítima não é levada em conta no processo de significação da justiça.

A posição de Aristóteles reflete, em grande parte, o pensamento filosófico clássico onde a alteridade era considerada uma dimensão acessória dentro de um sistema lógico. Nos sistemas filosóficos a alteridade é uma dimensão complementar de aspectos colaterais da reflexão lógico-conceitual.

\section{A justiça procedimental}

Na modernidade, os clássicos do contratualismo (Hobbes, Locke, Rousseau, etc.) desenvolveram uma teoria da justiça baseada fundamentalmente na teoria do contrato social. Esta perspectiva hermenêutica privilegia o procedimento como critério verificador da justiça, por isso é denominada de justiça procedimental.

A justiça procedimental operou um deslocamento do sentido clássico da justiça como virtude para os princípios e métodos de fazer a justiça. O justo, enquanto virtude moral, passou a ser considerado algo particular e válido só nas relações privadas porém insuficiente para delimitar a legitimidade das instituições sociais. A justiça foi significada de forma objetiva como um procedimento de administração da justiça. É o que se denomina de justiça procedimental. Ela se considera uma justiça objetiva, porque se administra de forma isonômica e com os mesmos critérios para todos os indivíduos.

Na modernidade, a justiça passou a se identificar com os métodos da sua administração, por isso se considera que ela é objetiva. O procedimento, para ser justo, deve ser universalizável e deve aplicar-se de igual modo para todos os sujeitos. A justiça procedimental é validada pela aplicação correta dos procedimentos. 
Há divergência quanto ao modo de legitimar os procedimentos da justiça, porém todas as visões procedimentalistas fundamentam a justiça diretamente nos procedimentos (utilitarismo) ou nos princípios que, por sua vez, legitimam o procedimentos (deontologia). John Rawls critica os procedimentos das éticas utilitaristas e teleológicas que só levam em conta os resultados das ações como critério de validação da justiça e não se preocupam com os princípios em que se fundamentam. "A característica mais surpreendente da visão utilitarista da justiça é que não importa, exceto de forma indireta, como se distribui a soma da satisfação dos indivíduos..." Contudo, Ralws não pretende negar o valor da justiça procedimental mas fundamentá-la em princípios universais. Seu objetivo é construir uma teoria substantiva da justiça que fundamente a validade dos métodos, a partir da universalidade dos princípios éticos. Uma teoria que ele denomina de justiça como imparcialidade: "A justiça como imparcialidade é um exemplo do que tenho chamado de teoria contratualista". Os princípios pensados por Rawls querem superar o desejo por não ser um critério universalizável porém, e contraditoriamente, contemplam o interesse particular como o elemento natural que regula a sua lógica. "São os princípios que as pessoas livres e interessadas em promover seus interesses aceitariam numa posição inicial de igualdade como definidores dos termos fundamentais de sua associação". ${ }^{8}$

O deslocamento de sentido operado pela justiça procedimental se tornou hegemônico na modernidade. A justiça moderna identifica a validez do justo com o procedimento objetivo através do qual se processam as decisões judiciais. Para a modernidade algo pode ser considerado justo quando forem observados os procedimentos corretos. A justiça se identifica tanto com a definição válida dos princípios que definem a aplicação dos procedimentos como com a implementação correta dos métodos estabelecidos. Um ato que não observe com correção todos os procedimentos da justiça será considerado, imediatamente, um ato falho de justiça ou um ato injusto. "Se pensamos que a justiça expressa sempre um tipo de igualdade, então a justiça formal exige que as leis e instituições se devam aplicar igualitariamente (ou seja, da mesma forma)". ${ }^{9}$

Essa perspectiva da justiça objetiva trouxe muitos elementos positivos que ajudaram a depurar a equanimidade das decisões judiciais e a discernir com mais clareza a aplicação de um ato justo ou injusto. A justiça procedimental tem elementos positivos, os quais devem ser assumidos como contribuições históricas que enriquecem o sentido da justiça. Porém, se faz necessário apontar algumas limitações da justiça procedimental que comprometem seriamente o próprio sentido da justiça. Tal análise crítica se faz mais urgente e necessária, haja vista que a justiça procedimental se consolidou de forma hegemônica em nossas sociedades e ela é que define a validade da justiça e conseqüentemente a legalidade.

RAWLS, John. Teoría de la justicia. México: FCE, 1985, p. 49.

Ibid., p. 21.

Ibid., p. $79-80$ 
A questão mais grave da justiça procedimental reside na própria (com)fusão que ela faz entre justiça e procedimento. A fusão orgânica de ambos os sentidos provocou uma série de mutilações no sentido da justiça cujo sentido ficou limitado pelo procedimento. Esse reducionismo afeta principalmente aqueles que são os destinatários principais da justiça, ou seja, as vítimas ou os injustiçados.

O reducionismo da justiça ao procedimento se manifesta com clareza quando se pretende identificar a justiça com a lei. Algo que já estava presente em Aristóteles, como vimos anteriormente. $\mathrm{O}$ procedimentalismo legal tende a vincular $\mathrm{O}$ justo com o legal considerando que a legalidade instituída pelos procedimentos corretos é sinônimo de justiça stricto sensu.

John Rawls analisa essa questão ao tratar dos Procedimentos da Justiça, constatando que no suposto de uma sociedade que tem uma estrutura básica de regras e procedimentos que satisfazem a aplicação da justiça, embora possamos discordar e rejeitar os princípios de sua justiça, estes devem ser considerados válidos, já que dentro desse sistema eles assumem o papel da justiça. Os procedimentos corretos designam uma distribuição justa de direitos e deveres fundamentais, determinando as vantagens e obrigações de cada um. ${ }^{10}$

A justiça identificada com a legalidade promove a obediência fiel à ordem vigente. Esee silogismo identificador da justiça com a legalidade dos procedimentos faz de justiça (procedimental) o principal símbolo legitimador da ordem estabelecida. No suposto anteriormente mencionado por Ralws, embora as regras, normas e leis vigentes possam nos parecer até injustas, uma vez que elas são aceitas com amplo consenso nessa sociedade e sendo administradas imparcialmente, elas são normas justas. Conclui Ralws: "Esta administração imparcial e conseqüente das leis e das instituições, quaisquer que sejam seus princípios substantivos, podemos chamar de justiça formal". ${ }^{11}$

Dentro da lógica do procedimentalismo a justiça se identifica com a lei, e a injustiça é definida como a transgressão da lei. A injustiça é correlativa à transgressão dos procedimentos e uma agressão contra a ordem estabelecida. "A justiça formal é a adesão a princípios, como disseram alguns, a obediência ao sistema". ${ }^{12}$

Para a justiça procedimental a pessoa da vítima ocupa um lugar secundário, em muitos casos quase que acessório. Nela, as regras, os procedimentos e leis são a referência primeira para definir o sentido do justo e do injusto. O sofrimento da vítima é só uma referência secundária ou um efeito colateral implícito na transgressão dos procedimentos. Conseqüentemente, a restauração do sofrimento da vítima também não se torna um objetivo prioritário da justiça, mas um efeito secundário da preservação da ordem. A vítima não é valorada em si mesma pela injustiça sofrida, ela é considerada secundariamente em relação à transgressão da lei. É a lei que define a vítima e determina os critérios pelos quais se reconhece a

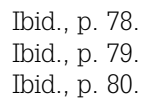


sua condição de injustiçada. Se porventura a injustiça cometida contra alguém não estivesse tipificada num ato legal, a injustiça não existiria ainda que existisse o injustiçado. Ou seja, a justiça procedimental considera que não houve injustiça, quando não há lei ou procedimento legal transgredido.

Para a justiça procedimental, a pessoa do injustiçado é um elemento acessório da lei. O deslocamento do sentido da justiça para o procedimento formal provocou uma hipertrofia legal que procura legislar ao máximo todos os atos da vida com o intuito de, através desta via, aumentar o poder legal da justiça. Essa inversão procedimental da justiça leva, entre outras conseqüências, a uma juridizição da vida social onde o direito impera como procedimento, substituindo a relação de alteridade e a capacidade de diálogo com o outro na resolução dos conflitos. Há uma tendência atual a reduzir as relações sociais aos procedimentos legais.

A redução da justiça à legalidade traz como conseqüência o esquecimento (consciente ou não) de que o sofrimento do injustiçado é o primeiro critério que define a injustiça e como contrapartida aquilo que deve ser considerado justo. Ao identificar a justiça com o procedimento, a modernidade deslocou a pessoa da vítima do foco central da justiça colocando em seu lugar o procedimento legal.

\section{A redução da justiça aos interesses do eu}

A justiça procedimental, já nos seus primórdios, operou um outro reducionismo ao fundamentar seus princípios e procedimentos no estado de natureza do eu ${ }^{13}$ ou mais recentemente se correlativo na categoria da posição original. ${ }^{14}$ A teoria contratualista e seu modelo de justiça legitimou as instituições sociais numa concepção de sujeito e no pressuposto antropológico de um estado de natureza original. "Para entender o poder político corretamente, e deriva-lo de sua origem, devemos considerar o estado em que todos os homens naturalmente estão". 15 Nesse hipotético estado de natureza, o sujeito é considerado auto-suficiente. A autosuficiência natural é enunciada como a condição de possibilidade da autonomia moral e social; a sociedade é produto resultante da decisão voluntária do indivíduo (o contrato). Desse modo a natureza auto-suficiente do sujeito moderno se constitui no princípio formal da justiça.

Para a modernidade, no estado de natureza, a alteridade é dispensável. O outro é absolutamente prescindível. A constituição da subjetividade do eu moderno desconhece a sua abertura necessária para o outro e não leva em conta a interdependência ontológica que vincula o sujeito com a alteridade do outro. "É um estado de perfeita liberdade para regular suas ações e dispor de suas posses do modo como julgarem acertado, dentro dos limites da lei da natureza, sem pedir licença

\footnotetext{
Hobbes, Thomas. El leviatan. Madrid: Altaya, 1997. p. 105-100.

RAWLS, John. Teoria de la justicia. México: FCE, 1985, p. 143-226.

LOCKE, John. Dois tratados sobre o governo. São Paulo: Martins Fontes, 2001, p. 381.
} 
ou depender da vontade de qualquer outro homem". ${ }^{16}$ Contudo, o eu só pode se constituir-se como sujeito social a partir da abertura para a alteridade do outro.

A ficção filosófica do estado de natureza fez uma permuta poucas vezes percebida; além de identificar a justiça com o procedimento, trocou a justiça pela igualdade. Considera-se que a condição original de igualdade natural é o ideal da justiça e que essa condição natural deve servir como marco regulador das relações sociais. A desigualdade social, embora seja vista como fruto da injustiça histórica, por exemplo, no caso de Rousseau, ${ }^{17}$ é algo irreparável que não é levado em conta como critério para pensar a justiça. Como a condição original de igualdade plena ou de justiça total é um ponto sem retorno, se propõe, desde diversas tentativas modernas, a criação de um contrato social que instituiria a sociedade a partir de um suposto ponto zero da história. Esse ponto zero do contrato social apaga a memória das vítimas e recoloca todos num novo e hipotético círculo do consenso procedimental onde os afetados podem (supostamente) deliberar em condição de igualdade sobre o futuro da sociedade. ${ }^{18}$

Seguindo os modelos contratualistas, John Rawls fundamenta sua teoria da justiça na hipótese da posição originária. A teoria da "justiça como imparcialidade" que ele preconiza tem como pressuposto a existência de um estado originário em que os sujeitos podem decidir racionalmente nas mesmas condições de igualdade, os princípios de justiça que devem ser aplicados. "Ao elaborar a justiça como imparcialidade, uma das tarefas principais é claramente a de determinar que princípios de justiça seriam escolhidos na posição original". ${ }^{19}$ Esse estado originário é um paralelo reformulado do estado de natureza. O sujeito natural que Ralws imagina tem nos interesses pessoais, ainda que mediados pela racionalidade, um dos critérios universalizáveis para formular os princípios de justiça. Para neutralizar o egoísmo implícito no interesse natural, Ralws imagina uma outra ficção antropológica do estado originário que denomina de véu de ignorância. ${ }^{20} \mathrm{O}$ véu de ignorância do estado originário possibilita que os sujeitos, dado que não sabem sua condição histórica e as vantagens pessoais que dela podem obter, devem legislar visando o bem comum como princípio de justiça. Esse véu de ignorância que o estado de natureza estende sobre os sujeitos, afeta diretamente a sua condição histórica. A história aparece como um elemento secundário da justiça. Em muitos casos é percebida como um componente perturbador da verdadeira justiça (procedimental). ${ }^{21}$

LOCKE, John, op. cit. p. 382.

ROUSSEAU, Jean-Jacques. Discours sur les sciences et les arts. Oeuvres Complètes. Tomo III, Paris: Gallimard, 1964, p. 160-164.

18 MATE, Reyes. Memórias depois de Auschwitz. São Leopoldo: Nova Harmonia, 2005, p. 261-280.

19 La justicia como imparcialidad. México: FCE, 1985, p. 31. A teoria de J. Rawls segue o marco conceitual comum da teoria contratualista da justiça, inerente à modernidade.

${ }^{20}$ RAWLS, John. Teorias de la justicia. México: FCE, 1985, p. 35-40.

21 É interessante constatar que Rawls percebe que a figura simbólica do véu da ignorância é também uma categoria epistemológica, antropológica e ética implícita nas principais éticas deontológicas: "A noção de véu da ignorância me parece estar implícita na ética de Kant (p. 40)...". RAWLS, John. La justicia como imparcialidad. México: FCE, 1985, p. 167. 
Embora Rawls procure estabelecer princípios substantivos da justiça que superem o utilitarismo e falta de universalidade das éticas teleológicas, esses princípios remetem ao modelo antropológico do eu moderno que desemboca no procedimentalismo. "A intenção de posição original é estabelecer um procedimento eqüitativo segundo o qual quaisquer que sejam os princípios conveniados, estes sejam aceitos". 22

Resumindo, podemos dizer que o sentido procedimental da justiça é correlativo ao modelo antropológico do sujeito moderno, que é concebido num estado de natureza auto-suficiente. Como conseqüência, os procedimentos da justiça remetem à preservação de sua natureza individualista e aos interesses a ela atribuídos. Para o sujeito moderno, a justiça é identificada com os procedimentos que garantem o que ele considera direitos do seu estado de natureza. Com isso, a justiça se reduz a um símbolo que prescreve a preservação dos interesses individuais, regulados pelos procedimentos legais, os quais instituem a ordem social. Em seu anverso, a injustiça passa a ser significada como a transgressão dessa ordem.

\section{A liberdade, uma prática de justiça}

A justiça procedimental contribui para definir com propriedade os procedimentos de administração da justiça, porém esses procedimentos, em muitos casos, resultam insuficientes para entender o significado da justiça para o injustiçado. A justiça da vítima desborda os formalismos procedimentais. Estes, embora sejam eficientes para cumprir a lei e manter a ordem, resultam, em muitos casos, insuficientes para restaurar a injustiça sofrida. A dor da vítima, o sofrimento do injustiçado requerem uma outra perspectiva da justiça. Se queremos compensar ao máximo a dor da vítima e restaurar, no possível, a injustiça sofrida, é necessário pensar uma nova perspectiva hermenêutica da justiça: a justiça das vítimas. Essa nova perspectiva da justiça deve ter como referência epistemológica a alteridade da vítima. Seu critério de significação deve ser restaurar o dano cometido pela injustiça.

Levinas é um dos pensadores que, com mais agudeza, desenvolveu o sentido da alteridade como dimensão primeira da existência humana. O Outro não é alguém dispensável mas a condição de possibilidade da existência da subjetividade. "A relação com o Outro me questiona, esvazia-me, descobrindo-me possibilidades sempre novas. Não me sabia tão rico, mas não tenho mais o direito de guardar alguma coisa". ${ }^{23}$ A relação com o outro é condição necessária do sujeito. Essa relação é sempre uma interpelação. No caso da vítima sua interpelação nos responsabiliza pela sua situação.

A interpelação do sofrimento da vítima é prévia à liberdade, interfere nela e a impele a decidir sobre a sua responsabilidade para com o outro injustiçado. A interpelação do outro antecede a sua liberdade. A alteridade do outro vitimado

Rawls, John. Teorías de la justicia. México: FCE, 1985, p. 163.

LEVINAS, Emmanuel. Humanismo do Outro Homem. RJ: Vozes, 1993, p. 56. 
invade a liberdade constituindo-a como uma liberdade responsável. O apelo do sofrimento do outro perfaz o sentido da decisão do sujeito. Ante a dor do Outro injustiçado, a decisão é sempre uma resposta, uma responsabilidade. Mesmo que a resposta seja a indiferença, esta o responsabiliza (como cúmplice) com a injustiça do outro.

A resposta para o outro injustiçado é a justiça. A interpelação do sofrimento do outro transforma a liberdade em compromisso de justiça. A liberdade, ante o outro vitimado, só pode exercer-se como resposta à interpelação da injustiça; conseqüentemente ela sempre será um tipo de (des)compromisso com o outro. Essa liberdade comprometida é a justiça. Justiça é a prática comprometida em prol do outro vitimado. A relação com o outro é uma forma de realizar justiça. "A responsabilidade é o que, de forma exclusiva, me incumbe e que, humanamente, eu não posso rejeitar. Essa carga é uma suprema dignidade do único. Eu não posso me trocar, eu sou na medida em que sou responsável". ${ }^{4}$

A liberdade é sempre uma prática, ela não existe como essência metafísica da natureza humana. De igual modo, a justiça é sempre uma prática que se implementa em relação à injustiça sofrida pela vítima. A justiça é sempre uma responsabilidade ética pelo outro. Levinas apontou para o fato de que, se a alteridade é condição de possibilidade da constituição da subjetividade, a ética se constitui na dimensão primeira (metafísica) da existência humana. ${ }^{25}$ A relação com o outro é sempre uma forma de responsabilidade e por isso uma relação ética. No caso da vítima, essa relação se transforma em uma interpelação para o compromisso.

A alteridade é a dimensão constitutiva da subjetividade, ela não é uma ficção filosófica como o estado de natureza nem um artifício procedimental como a posição original. A alteridade é uma realidade histórica em cada sujeito, porém universal porque constitui a humanidade de todos os sujeitos. Ela é sempre abertura relacional, consequentemente ética. É a referência que nos possibilita pensarmos um critério universal e histórico para a justiça.

Afirmar a liberdade como compromisso de justiça não significa negar o valor (simbólico) da liberdade. O que está em questão é o sentido ego-ísta da liberdade tão íntimo à modernidade. A liberdade só adquire sentido como prática e em relação ao outro. O indivíduo auto-suficiente do estado de natureza nunca existiu e não pode existir. Essa foi uma ficção antropológica que se transformou num artifício ideológico para legitimar o individualismo moderno. "A unicidade do eu, o seu estatuto de indivíduo sem conceito, desapareceria na participação naquilo que o ultrapassa" ${ }^{26}$ A liberdade natural do indivíduo auto-suficiente não tem correspondência histórica possível. Essa liberdade é uma ficção metafísica inexistente.

A liberdade só existe como prática realizada num contexto histórico. A historicidade a situa sempre numa relação de alteridade, já que o sujeito só existe em relação aos outros, e sua liberdade se exerce como prática que efetiva essa relação

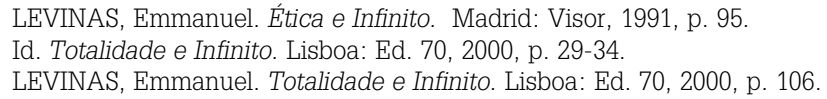


de alteridade. Desde esta perspectiva, perde sentido o axioma individualista do liberalismo moderno: a minha liberdade termina onde começa a liberdade do outro. O outro não é o limite da minha liberdade senão a condição de sua realização. De igual forma podemos inverter esse axioma dizendo que a minha liberdade se expande com a liberdade do outro e a realiza na forma de prática de justiça. "O outro absolutamente outro - outrem - não limita a liberdade do mesmo. Chamando-o à responsabilidade, implanta-a e justifica-a. "27

A liberdade está vinculada a uma realização histórica da subjetividade. Esta, por sua vez, só pode realizar-se em relação ao Outro. O Outro é a condição de possibilidade da realização do sujeito que leva consigo um apelo para a responsabilidade. "No último caso, justificar a liberdade não é demonstrá-la mas torná-la justa." 28

\section{A justiça das vítimas}

Se pensarmos a alteridade como a dimensão primeira da existência humana, a justiça não pode identificar-se com o procedimento. Ela deve ter como referência primeira a alteridade do outro vitimado. O que define o ser da justiça, em primeira instância, não são os interesses do eu nem os princípios que deles se possam derivar, mas a injustiça sofrida pela vítima. A justiça é, em primeira instância, correlativa à injustiça e não aos interesses universalizáveis do eu. O sentido do justo está vinculado, em primeiro lugar, à injustiça cometida contra o outro. O sofrimento do injustiçado, sua alteridade negada, deve ser a primeira referência do sentido da justiça.

O outro, na condição de vítima, se insurge (re)clamando justiça. Sua alteridade negada se sobrepõe, como realidade primeira, às outras perspectivas da justiça. É nela que os outros sentidos da justiça devem procurar ressignificar-se. A justiça procedimental e a prática da virtude têm validade ética enquanto acorrem a suplementar o sentido primeiro da justiça, que é restaurar a injustiça da vítima.

A justiça das vítimas excede os procedimentos e só se realiza no compromisso histórico por restaurar a injustiça cometida. A justiça das vítimas (me) responsabiliza com o sofrimento dos injustiçados. Esta é uma justiça que só se realiza como compromisso ético e que não pode ser reduzida a mero ato procedimental. Desde a perspectiva das vítimas, a ética se constitui na relação primeira do ser humano. Daí que a justiça das vítimas se torna a condição de possibilidade da

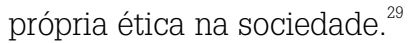

O termo "justiça das vítimas" não deve ser entendido no sentido objetivo da justiça feita pelas vítimas, mas no genitivo da justiça devida às vítimas. No sentido objetivo, a justiça feita pelas vítimas substituiria os procedimentos objetivos da justiça e se deslizaria para numa justiça subjetiva que facilmente cairia na vingan-

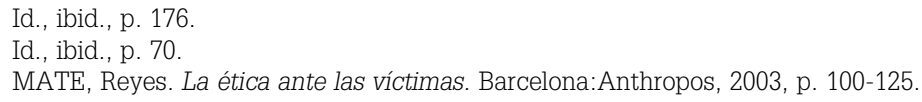


ça. No sentido genitivo, a justiça das vítimas é o critério hermenêutico, a partir do qual deve significar-se o sentido da justiça e para o qual devem confluir, de forma subsidiária, tanto a justiça objetiva do procedimentalismo como a prática da virtude.

A justiça (re)clamada pela vítima não se instaura com o ato procedimental da punição do culpado; a injustiça sofrida não se restaura com a recomposição da ordem. Sua alteridade negada é a perspectiva ético-epistemológica que deve servir de referência hermenêutica para definir o sentido da justiça. Justo é devolver a dignidade negada ao injustiçado, justiça é reconhecer e restaurar a alteridade humilhada da vítima. O clamor do injustiçado não é um referencial secundário do procedimento, ele é interpelação histórica e critério universal para definir a justiça. "O outro enquanto outro é Outrem. Requer-se a relação do discurso para 'deixarser'; o 'desvelamento' puro onde ele se propõe como tema, não o respeita suficientemente para isso. Chamamos de justiça o acolhimento de frente, no discurso. Se a verdade surge na experiência absoluta em que o ser brilha com a sua própria luz, a verdade só se produz no verdadeiro discurso ou na justiça". ${ }^{30}$

O sentido do justo supera o procedimento de aplicação da justiça e remete à restauração histórica da injustiça cometida contra a vítima. ${ }^{31}$ Sem a reparação real da injustiça histórica, sem o reconhecimento efetivo da alteridade negada da vítima, a justiça se converte em aparato procedimental, num artifício ideológico que serve para legitimar a ordem vigente e, no pior dos casos, é utilizada para salvaguardar os interesses das classes dominantes.

A justiça quando significada desde a alteridade do outro injustiçado, adquire um sentido universal e histórico ao mesmo tempo. A alteridade da vítima é um critério universal e universalizável, porém a injustiça de cada vítima é uma situação histórica particular. "Ouvir a sua miséria que clama por justiça não consiste em representar-me uma imagem, mas em colocar-me como responsável...". ${ }^{32} \mathrm{~A}$ justiça está indissociavelmente ligada à pessoa do injustiçado. Só se faz justiça quando se consegue reparar a injustiça cometida. Por sua vez a injustiça só se repara quando se resgata a vítima de sua condição de injustiçada, devolvendo-lhe a plenitude de sua alteridade negada.

Ao pensarmos a justiça a partir do outro injustiçado, fica evidente o reducionismo que a modernidade operou, quando (con)fundiu a justiça com o procedimento. Contrariando a tendência da modernidade, a injustiça acontece, não contra a regulamentação legal, mas quando se comete uma violação da alteridade humana, ou seja, ao provocar o sofrimento injusto do inocente.

A justiça das vítimas é interpelação e responsabilidade, é compromisso com a restauração da injustiça histórica cometida contra elas. Este novo sentido de justiça excede a significação dos princípios procedimentais e remete sempre à condi-

LEVINAS, Emmanuel. Totalidade e Infinito. Lisboa: Ed. 70, 2000, p. 58

1 SUCASAS, Alberto. "Interpelación de la víctima e exigencia de justicia". In MATE, Reyes (Org.) La ética ante las víctimas. Barcelona; Anthropos, 2003, p. 76-100.

32 LEVINAS, Emmanuel. Totalidade e Infinito. Lisboa: Ed. 70, 2000, p. 193. 
ção de alteridade do outro vitimado. "A significação significa na justiça mas também - a justiça perpassa a justiça e minha responsabilidade para com o outro, na minha desigualdade para aquele de quem eu sou refém". ${ }^{33}$

A interpelação da vítima é a justiça primeira, ela é a condição de possibilidade da realização histórica da ética. Se a justiça das vítimas for negada, ignorada ou apagada, todo o edifício social será levantado sobre uma falácia ética, uma injustiça. As instituições sociais se sustentarão sobre alicerces procedimentais ou argumentativos de areia, e os próprios atos de justiça institucional ou social ficarão viciados, não por um defeito de forma, mas por uma injustiça de fundo.

Se a justiça das vítimas não for incorporada como justiça primeira, a ética será, simplesmente, esvaziada. Sem a justiça primeira exigida pelas vítimas, os fundamentos éticos de qualquer relação social ou de qualquer instituição se converterão em aparatos simbólicos de legitimação do poder. Sua estrutura ética estará corroída pela injustiça primeira de negar o reconhecimento (e a justiça) aos injustiçados. A ética será mera retórica procedimental e o procedimentalismo se converterá numa retórica vazia. "A natureza da retórica (da propaganda, da lisonja, da diplomacia, etc.) consiste em corromper a liberdade. É por isso que ela é violência por excelência, ou seja, injustiça". ${ }^{34}$

\section{Referências}

ARISTÓTELES. Ética a Nicómaco. Madri: Espasa Calpe, 1993.

ARISTÓTELES. Ética Nicomacaquea. Madri: Gredos, 2000.

HOBBES, Thomas. El leviatan. Madri: Altaya, 1997.

LEVINAS, Emmanuel. De otro modo que ser; o más allá de la esencia. Salamanca: Sígueme, 1987. . Ética e Infinito. Madri: Visor, 1991

. Humanismo do Outro Homem. Vozes: RJ, 1993.

Totalidade e Infinito. Lisboa: Ed. 70, 2000.

Ética e Infinito. Lisboa: Ed. 70, 2000.

LOCKE, John. Segundo Tratado do Governo Civil. São Paulo: Martin Fontes, 2001.

MATE, Reyes (org.) La ética ante las víctimas. Barcelona; Anthropos, 2003.

MATE, Reyes. Memórias depois de Aushwitz. São Leopoldo: Nova Harmonia, 2005.

RAWLS, John. La justicia como imparcialidad. México: FCE, 1985. Teorias de la justicia. México: FCE, 1985.

ROUSSEAU, Jean-Jacques. Discours sur les sciences et les arts. Oeuvres Complètes. Tomo III, Paris: Gallimard, 1964.

33 LEVINAS, Emmanuel. De otro modo que ser; o más allá de la esencia. Salamanca: Sígueme, 1987, p. 237.

LEVINAS, Emmanuel. Totalidade e Infinito. Lisboa: Ed. 70, 2000, p. 57. 